\title{
DESCRIÇÃO ANATÔMICA DO LENHO DE BRUNFELSIA AUSTRALIS BENTHAM (SOLANACEAE) ${ }^{1}$
}

\author{
ANELISE MARTA SIEGLOCH ${ }^{2}$ SIDINEI RODRIGUES DOS SANTOS ${ }^{3}$ \\ JOSÉ NEWTON CARDOSO MARCHIORI ${ }^{4}$
}

\section{RESUMO}

A estrutura anatômica do lenho de Brunfelsia australis Bentham é descrita, a partir de material proveniente do Rio Grande do Sul. Os principais caracteres anatômicos observados incluem: porosidade difusa; poros exclusivamente solitários; elementos vasculares de comprimento médio; placas de perfuração simples; pontoações intervasculares pequenas e alternas; parênquima paratraqueal escasso e apotraqueal difuso; raios heterogêneos; fibras de comprimento médio, com pontoações areoladas e paredes finas a espessas.

Palavras-chave: Brunfelsia australis, anatomia da madeira, Solanaceae.

\section{ABSTRACT}

\section{[Wood anatomy of Brunfelsia australis Bentham (Solanaceae)].}

The anatomical structure of Brunfelsia australis is described, based on a sample of wood collected in Rio Grande do Sul state, Brazil. The main anatomical features include: diffuse porous wood; exclusively solitary pores; medium size vascular elements; simple perforation plates; small and alternate intervessel pits; scarce paratracheal and diffuse apotracheal parenchyma; heterogeneous rays; medium size fibres, with thin to thick walls and bordered pits.

Key words: Brunfelsia australis, wood anatomy, Solanaceae.

\section{INTRODUÇÃO}

As Solanaceae compreendem 22 gêneros e cerca de 114 espécies de ervas, arbustos e árvores, no Rio Grande do Sul. Pertencente a esta família botânica, o gênero Brunfelsia Swartz reúne umas 22 espécies de arvoretas ou arbustos da América tropical, cuja morfologia externa apresenta caracteres peculiares e constantes, dificultando a identificação de suas espécies (Soares, 2006). Entre outros aspectos mor-

1 Recebido para publicação em 06/09/2009 e aceito para publicação em 12/11/2009.

2 Acadêmica do Curso de Graduação em Engenharia Florestal, Universidade Federal de Santa Maria, CEP $97105-$ 900, Santa Maria, RS, Brasil.

3 Biólogo, bolsista do CNPq - Brasil, doutorando do Programa de Pós-Graduação em Engenharia Florestal, Departamento de Ciências Florestais, Universidade Federal de Santa Maria, CEP 97105-900, Santa Maria, RS, Brasil.

${ }^{4}$ Engenheiro Florestal, Dr., bolsista de Produtividade em Pesquisa (CNPq - Brasil), Professor Titular do Departamento de Ciências Florestais, Universidade Federal de Santa Maria. Santa Maria, RS, Brasil. balduinia@mail.ufsm.br fológicos, destacam-se as folhas inteiras, flores actinomorfas de cálice tubuloso, 5-lobado, corola hipocrateriforme e frutos capsulares subcarnosos (Dimitri, 1980).

A flora sul-rio-grandense inclui apenas 3 espécies de Brunfelsia, conhecidas, popularmente, como manacá ou primavera.Valorizadas como ornamentais, devem seu prestígio ao efeito inconfundível da variação cromática de suas flores, que vão do azul ao violeta no início da floração, tornando-se esbranquiçadas mais tarde (Soares, 2006).

Das espécies nativas, Brunfelsia australis Benth. é a mais difundida em floricultura. Trata-se de arbusto ou árvore pequena (até $4 \mathrm{~m}$ ), nativa no Paraguai, Uruguai, Argentina e Brasil, de São Paulo ao Rio Grande do Sul (Sobral et al., 2006); neste estado habita, sobretudo, o interior e clareiras de diferentes formações florestais, nas regiões fisiográficas do Alto Uruguai, Planalto Médio, Encostas Inferior e Superior do Nordeste, Depressão Central, Missões, Encosta do Sudeste e Litoral. Frequentemente 
confundida com B. pilosa e, principalmente, com B. uniflora, a espécie em estudo difere pelas folhas obovadas, pelas inflorescências raramente unifloras e pelo cálice campanulado, glabro (Soares, 2006).

O presente estudo, que trata da descrição anatômica do lenho de Brunfelsia australis Benth., visa a contribuir ao conhecimento estrutural das Solanaceae nativas.

\section{REVISÃO DE LITERATURA}

Não foram encontradas referências anatômicas sobre madeiras de Brunfelsia, inclusive em obras clássicas, como Metcalfe \& Chalk (1972) e Record \& Hess (1943).

Para o conjunto das Solanaceae, no entanto, são mencionados nas referidas obras: anéis de crescimento distintos; vasos muito pequenos a grandes, variando de muito poucos até numerosos; vasos em pequenos agrupamentos ou múltiplos radiais curtos até longos; elementos vasculares de comprimento médio a moderadamente curtos; placas de perfuração simples; pontoações intervasculares alternas, diminutas a grandes; espessamentos espiralados geralmente ausentes; parênquima axial pouco abundante, nos arranjos apotraqueal difuso e paratraqueal escasso até vasicêntrico; raios heterogêneos, exclusivamente unisseriados ou com até 8 células de largura, por vezes em dois tamanhos distintos; pontoações raios-vasculares médias a grandes, arredondadas e alternas, por vezes alongadas; fibras com pontoações areoladas ou inconspicuamente areoladas, de paredes finas a moderadamente espessas, por vezes muito espessas, raramente com septos; e séries cristalíferas ocasionais, no parênquima axial.

\section{MATERIAL E MÉTODOS}

O material examinado consiste de uma amostra de madeira e respectiva exsicata botânica, conservados no Herbário do Departamento de Ciências Florestais da Universidade Federal de Santa Maria (HDCF), sob o número 2979. O material procede de São Vicente do Sul, cons- tando na etiqueta de herbário os seguintes dados: Cerro Loreto, muito abundante na submata, Marchiori, J.N.C., 04-10-1986, madeira coletada.

Para a descrição anatômica, foram confeccionadas lâminas histológicas e também de macerado. Na confecção das lâminas de cortes anatômicos, seguiu-se a técnica padrão do Laboratório de Anatomia da Madeira da Universidade Federal do Paraná: as amostras foram amolecidas por fervura em água e seccionadas em micrótomo de deslizamento, regulado para a obtenção de cortes com $20 \mu \mathrm{m}$ de espessura. Os cortes foram tingidos com acridina-vermelha, crisoidina e azul-de-astra (Dujardin,1964), desidratados em série alcoólica-ascendente $(30 \%, 50 \%, 70 \%, 95 \%$ e duas vezes em álcool absoluto), diafanizados em xilol e montados em lâminas permanentes, com "Entellan". Para as lâminas de macerado, usou-se o método de Jeffrey (Burger \& Richter, 1991) e coloração da pasta com safranina $1 \%$; na montagem das lâminas, seguiu-se, em princípio, o método acima referido, com a diferença de que as três primeiras etapas foram desenvolvidas em papel filtro.

A descrição microscópica da madeira baseou-se nas normas do IAWA Committee (1989). Para as percentagens de tecidos, usou-se um contador de laboratório e 600 determinações ao acaso, conforme Marchiori (1980). A freqüência de poros $/ \mathrm{mm}^{2}$ foi obtida de forma indireta, a partir de um quadrado de área conhecida, superposto a fotomicrografias de seções transversais da madeira. As medições foram realizadas no Laboratório de Anatomia da Madeira, da Universidade Federal de Santa Maria, em microscópio Carl Zeiss, com ocular de escala graduada. As fotomicrografias foram tomadas em microscópio Olympus cx 40, com câmera digital Olympus Camedia c3000 acoplada.

\section{DESCRIÇÃO ANATÔMICA}

Madeira de porosidade difusa. Anéis de crescimento delimitados, fracamente, por fina ca- 
mada de fibras radialmente estreitas. (Figura 1A).

Vasos: muito numerosos a extremamente numerosos $\left(105 \pm 6,8(94-112)\right.$ poros $\left./ \mathrm{mm}^{2}\right)$, ocupando $14,7 \pm 4 \%$ do volume da madeira. Poros exclusivamente solitários, ligeiramente poligonais, muito pequenos $(34,8 \pm 6,5(22,5-$ 45) $\mu \mathrm{m})$ e de paredes espessas $(3,5 \pm 0,79(2,5$ $-5,0) \mu \mathrm{m})$. Poros sem padrão definido de organização, mas com tendência a alinhamento tangencial no início do anel de crescimento (Figura 1A,B). Elementos vasculares de comprimento médio $(511,6 \pm 86,5(330-640) \mu \mathrm{m})$, com placas de perfuração simples e apêndices geralmente em ambas as extremidades. Espessamentos espiralados ausentes. Pontoações intervasculares pequenas $(4,7 \pm 0,53(4,1$ - 5,1) $\mu \mathrm{m}$ ), alternas, circulares, com abertura em fenda inclusa. Pontoações raio-vasculares com aréolas distintas, semelhantes às intervasculares $(4,2 \pm 0,90(3,1-5,1) \mu \mathrm{m})$, mais freqüentes nas margens.

Parênquima axial: representando 6,8 $\pm 0,98 \%$ do volume da madeira; pouco distinto das fibras e em arranjos apotraqueal difuso e paratraqueal escasso (Figura 1A,B). Séries parenquimáticas compostas de $2-5$ células, medindo 330,8 \pm 98,2 (140 - 562,5) $\mu \mathrm{m}$ de altura (Figura 1F).

Raios: muito numerosos $(15 \pm 1,2(13-17)$ raios / $\mathrm{mm}$ ), ocupando $22,8 \pm 4,8 \%$ do volume da madeira. Tecido radial heterogêneo, reunindo células procumbentes, na parte multisseriada, e $1-6$, mais comumente 1 - 3 fileiras marginais de células quadradas e, principalmente, eretas; células procumbentes maiores do que as do corpo central, também presentes, embora pouco freqüentes (Figura 1C,D). Raios estreitos, com $1-4$, raro 5 células de largura, compondo dois grupos distintos, devido à escassez dos bisseriados (Figura 1E,F). Raios multisseriados, com 10-23, mais comumente 13 - 16 células e $394 \pm 99(250-620) \mu \mathrm{m}$ de altura; margens unisseriadas, geralmente menores do que o corpo. Raios unisseriados com 1 - 7 (13) células e
$326 \pm 115(150-570) \mu \mathrm{m}$ de altura. Conteúdo de coloração amarelada, escasso. Células radiais de paredes disjuntas, presentes. Raios axialmente fusionados, raios agregados, células envolventes e células perfuradas, ausentes.

Fibras: com pontoações distintamente areoladas e aberturas cruzadas, nas faces radiais e tangenciais da parede. Tecido fibroso representando $55,7 \pm 5,2 \%$ do volume da madeira. Fibras de comprimento médio $(1136,8 \pm 114$ $(940-1360) \mu \mathrm{m}), \operatorname{com} 24,8 \pm 3,9(17,5-35)$ $\mu \mathrm{m}$ de largura, e paredes finas a espessas $(5,7 \pm$ $2,9(2,5-8,7) \mu \mathrm{m})$ (Figura 1B). Fibras septadas, fibras gelatinosas e espessamentos espiralados, ausentes. Traqueídeos ausentes.

Demais caracteres: variantes cambiais, tubos laticíferos e taniníferos, canais intercelulares, células oleíferas, células mucilaginosas, estratificação e cristais, ausentes. Máculas medulares presentes.

\section{ANÁLISE DA ESTRUTURA ANATÔMICA}

As principais características anatômicas do lenho de Brunfelsia australis estão de acordo com as possibilidades estruturais relacionadas por Record \& Hess (1949) e Metcalfe e Chalk (1972) para as Solanaceae: poros muito pequenos; elementos vasculares médios; placas de perfuração simples; espessamentos espiralados ausentes; pontoações intervasculares alternas; parênquima axial escasso e difuso; raios heterogêneos, em dois tamanhos distintos; e fibras não septadas, de paredes finas a espessas. $\mathrm{O}$ comprimento médio das fibras $(1137 \mu \mathrm{m})$, todavia, resulta um pouco superior ao referido pelos autores $(700-950 \mu \mathrm{m})$.

Vasos exclusivamente solitários, pontoações intervasculares e raio-vasculares pequenas, bem como fibras com pontoações areoladas, são de ocorrência mais restrita na família, de acordo com Record \& Hess (1949) e Metcalfe \& Chalk (1972), motivo pelo qual resultam interessantes sob o ponto de vista taxonômico.

A presença de apêndices em elementos vasculares e de células radiais de paredes 

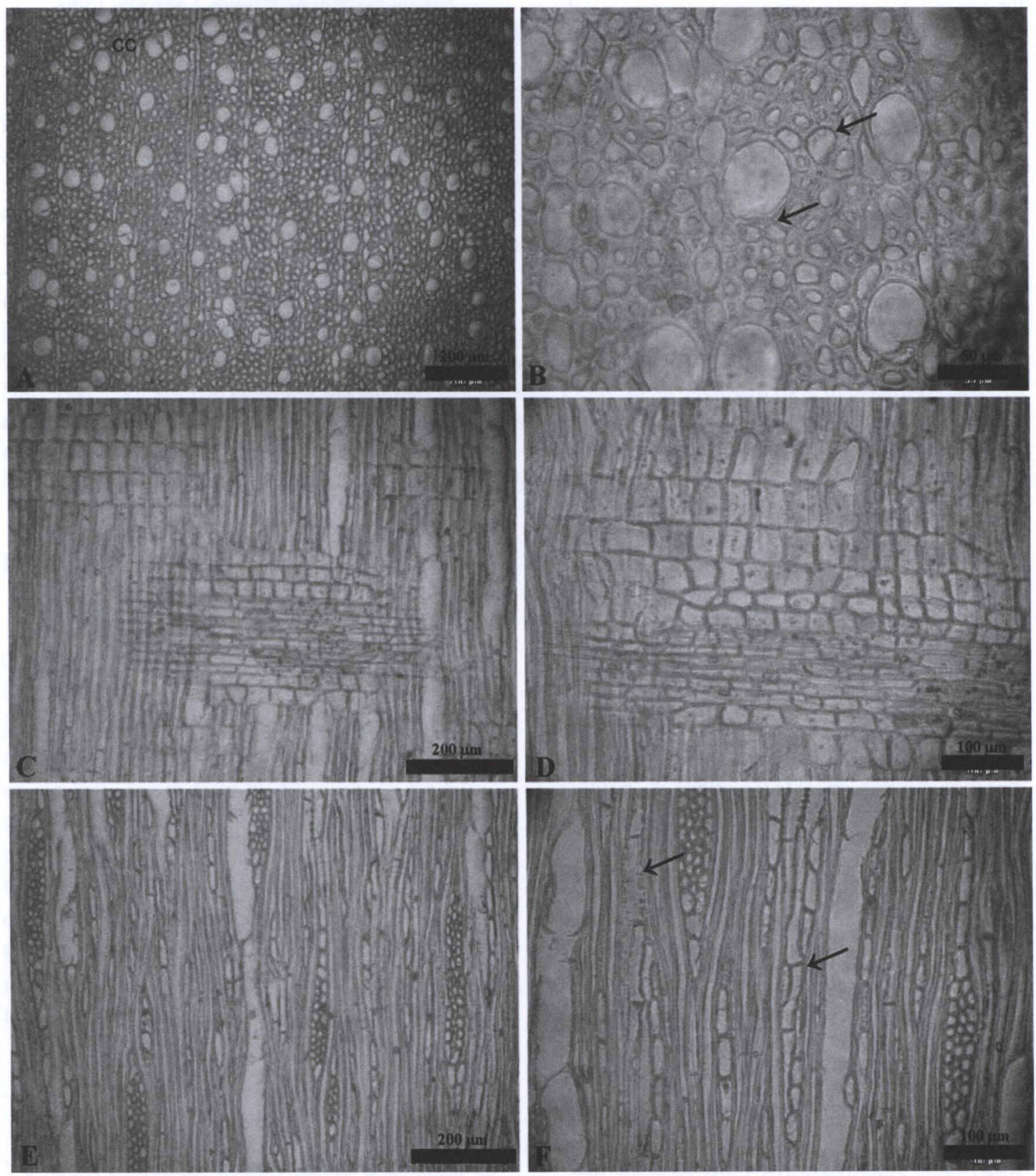

FIGURA 1 - Fotomicrografias da madeira de Brunfelsia australis. A - Limite de anel de crescimento fracamente delimitado (cc), porosidade difusa e poros exclusivamente solitários, ligeiramente poligonais (secção transversal). B - Mesma seção, com destaque para os parênquimas apotraqueal difuso e paratraqueal escasso (setas). C - Aspecto geral de raio heterogêneo, com células procumbentes (no corpo) e margens de células quadradas, eretas e procumbentes (seção longitudinal radial). D - Mesma seção, em maior aumento. E - Seção longitudinal tangencial, mostrando raios uni e multisseriados. F - Mesma seção, em maior aumento, com destaque para as séries de parênquima axial (seta) e raios de dois tamanhos distintos. 
disjuntas, não são mencionados na literatura consultada, constituindo novidade para a família.

\section{REFERÊNCIAS BIBLIOGRÁFICAS}

BURGER, L.M.; RICHTER, H.G. Anatomia da Madeira. São Paulo: Ed. Nobel, 1991. 154 p.

DIMITRI, M. J. Enciclopedia argentina de Agricultura y Jardineria. Buenos Aires: Editorial ACME, 1980. v. 2. p. 955.

DUJARDIN, E. P. Eine neue Holz-Zellulosenfaerbung. Mikrokosmos, n. 53, p. 94, 1964.

IAWA COMMITTEE. IAWA list of microscopic features for hardwood identification. IAWA Bulletin, v.10, n. 3, p. 218-359, 1989.

MARCHIORI, J. N. C. Estudo anatômico do xilema secundário de algumas espécies dos gêneros Acacia e Mimosa, nativas no Estado do Rio
Grande do Sul. 1980. 186f. Dissertação (Mestrado em Engenharia Florestal) - Universidade Federal do Paraná. Curitiba, 1980.

METCALFE, C.R.; CHALK, L. Anatomy of the Dicotyledons. Oxford: Clarendon Press, 1972. v. 2. p. 965-978.

RECORD, S.J.; HESS, R.W. Timbers of the New World. New Haven: Yale University Press, 1949. $640 \mathrm{p}$.

SOBRAL, M.; JARENKOW, J.A.; BRACK, P.; IRGANG, B.; LAROCCA, J.; RODRIGUES, R.S. Flora arbórea e arborescente do Rio Grande do Sul, Brasil. São Carlos: RIMA: Novo Ambiente, 2006. 350 p.

SOARES, E.L.C. Estudos taxonômicos em espécies de Solanaceae lenhosas no estado do Rio Grande do Sul, Brasil. 2006. 230f. Dissertação (Mestrado em Botânica) - Universidade Federal do Rio Grande do Sul, Porto Alegre, 2006. 